\title{
Effect of high strain rate on micro-indentation test in pure aluminum
}

\author{
H. Yamada ${ }^{1}$, N. Ogasawara ${ }^{1}$, Y. Shimizu ${ }^{2}$, H. Horikawa ${ }^{3}$, and H. Kobayashi ${ }^{3}$ \\ ${ }^{1}$ National Defense Academy, School of Systems Engineering, 1-10-20 Hashirimizu Yokosuka Kanagawa, Japan \\ ${ }^{2}$ National Defense Academy, Graduate Student, School of Systems Engineering, 1-10-20 Hashirimizu Yokosuka \\ Kanagawa, Japan \\ ${ }^{3}$ Osaka University, Graduate School of Engineering Science, 1-3 Machikaneyama Toyonaka Osaka, Japan
}

\begin{abstract}
The indentation properties of pure aluminum $(99.9 \%, 3 \mathrm{~N}$ aluminum) and high purity aluminum $(99.999 \%, 5 \mathrm{~N}$ aluminum) with respect to the strain rate dependence of strength are experimentally investigated in order to clarify the effect of strain rate on the micro-indentation test. A micro-indentation test using a Berkovich indenter was performed at loading rates of $0.7,7$, and $70 \mathrm{mN} / \mathrm{s}$. In all of the specimens, the indenter was loaded to a maximum value of $1200 \mathrm{mN}$, and then was maintained for $30 \mathrm{~s}$. In the $3 \mathrm{~N}$ specimen, the dependence of the loading rate on the load was slight at loading rates of 0.7 and $7 \mathrm{mN} / \mathrm{s}$, whereas the load at the loading rate of $70 \mathrm{mN} / \mathrm{s}$ was higher than the loads at loading rates of 0.7 and $7 \mathrm{mN} / \mathrm{s}$. On the other hand, the load for the $5 \mathrm{~N}$ specimen increased with the increasing loading rate. Thus, the effect of the loading rate on the load-displacement curve for the $3 \mathrm{~N}$ and $5 \mathrm{~N}$ specimens was similar to the strain rate dependence of strength for theses metals. In addition, the micro-indentation test was demonstrated to be strongly affected by high strain rate at a loading rate of $70 \mathrm{mN} / \mathrm{s}$.
\end{abstract}

\section{Introduction}

Instrumented indentation tests are widely used to investigate the elastic and plastic properties (indentation properties) of mechanical materials [1-3]. During an indentation experiment, a rigid indenter penetrates normally into a homogeneous solid, where the indentation load and displacement are continuously recorded during loading and unloading.

In the micro-indentation test, the hardness has been reported to increase with decreasing indentation depth $[4,5]$ based on the strain rate. Doerner and Nix [4] pointed out that the material strength was affected by the strain rate in the indentation test. When the indentation test is performed at a constant displacement rate, the strain rate can be defined as follows:

$$
\dot{\varepsilon}=c\left(\frac{1}{h} \frac{d h}{d t}\right)
$$

where $c$ is the material constant and $h$ is the indentation depth. Thus, equation (1) indicates that the strain rate becomes very high as the indentation depth decreases.

In a previous study, the authors [6] have investigated the effect of high strain rate (dynamic strain rate) on indentation properties by comparing the results of a microindentation test at a loading rate of $70 \mathrm{mN} / \mathrm{s}$ and the results obtained by the finite element method (FEM) analysis using the pure copper (rolled copper and annealed copper) having strain rate dependence of strength. Figure 1 shows the load-displacement curves of the micro-indentation test and the FEM analysis for rolled copper and annealed copper [6]. The load-displacement curves obtained through the static-FEM analysis were inconsistent with those obtained through the micro-indentation test for both rolled copper and annealed copper. As a result of the static-FEM analysis, the strain rate at the early stage of testing reached the dynamic strain rate, approximately $10 \mathrm{~s}^{-1}$, underneath the sharp indenter in the micro-indentation test. The CowperSymonds model, which includes the strain rate dependence of strength, was then used in the dynamic-FEM analysis (LS-DYNA). The load-displacement curves calculated by the Cowper-Symonds model showed good agreement with the experimental results for both rolled copper and annealed copper. Thus, the indentation properties were affected by the dynamic strain rate.

In the present study, the indentation properties of the pure aluminum with the strain rate dependence of strength (99.9 mass\% and 99.999 mass\% pure aluminum) were experimentally investigated in order to clarify in greater detail the effect of high strain rate on the micro-indentation test.

\section{Experimental details}

\subsection{Materials}

Two types of pure aluminum with 99.9 mass $\%$ (hereinafter, mass \% is referred to simply as \%) purity (3N aluminum) and 99.999 mass\% purity (5N aluminum: high-purity aluminum) were prepared. Compression test pieces with a gage length of $6.0 \mathrm{~mm}\left(l_{s}\right)$ and a diameter of $8.0 \mathrm{~mm}$ were machined using a lathe.

In the indentation test, the surface roughness of material was affected by the indentation properties. Thus, in the specimens using the indentation test, one surface was polished using emery paper (\#2000) and was buffed with alumina pastes (diameters of $1 \mu \mathrm{m}$ and $0.3 \mu \mathrm{m}$ ) to reduce the effect of surface roughness on the indentation properties.

All of the specimens were annealed at $623 \mathrm{~K}$ for $2 \mathrm{~h}(\mathrm{O}$ temper) to remove the work-hardened layer [7] before the compression and the indentation test. 


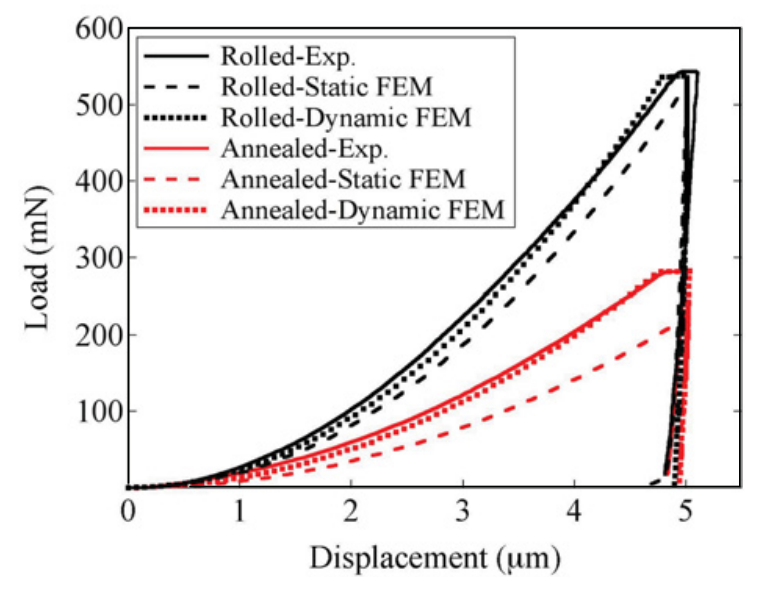

Fig. 1. Load-displacement curves obtained through a microindentation test and FEM analysis (static and dynamic) for rolled copper and annealed copper at a loading rate of $70 \mathrm{mN} / \mathrm{s}$ [6].

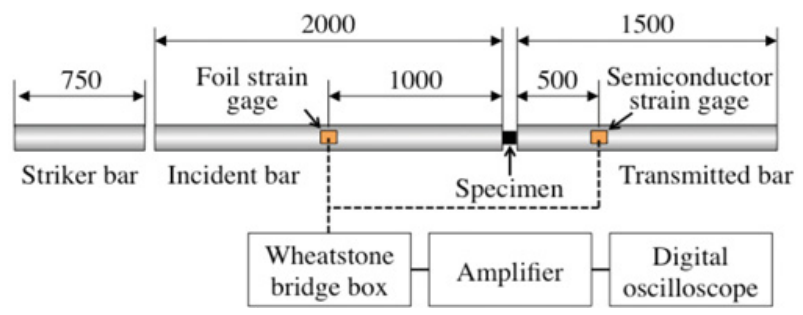

Fig. 2. Setup of the SHPB compression test. (Unit: $\mathrm{mm}$ )

\subsection{Compression test}

\subsubsection{Quasi-static test}

A quasi-static compression test (hereinafter referred to as the QS test) was carried out using an Instron-type universal testing machine at strain rates of $1.4 \times 10^{-4}, 1.4 \times 10^{-3}$, and $1.4 \times 10^{-2} \mathrm{~s}^{-1}$.

\subsubsection{Impact test}

In the present study, the impact compression test was performed using the split Hopkinson pressure bar (SHPB) method [8,9]. Dynamic stress-strain curves can be obtained by incorporating the elementary one-dimensional elastic wave propagation theory [10-12] into the SHPB method.

Figure 2 shows the setup of the SHPB apparatus for the impact compression test. This apparatus consists primarily of a striker bar, an incident bar, a transmitted bar, and an associated recording system (Wheatstone bridge box, differential amplifier, and digital oscilloscope). These bars are $14 \mathrm{~mm}$ in diameter. The specimen is sandwiched between the incident bar and the transmitted bar.

When a striker bar impacts an incident bar, a compression stress wave propagates through the incident bar. When the compression stress wave reaches the specimen, part of the stress wave is reflected at the specimen, whereas the remaining part of the stress wave propagates through

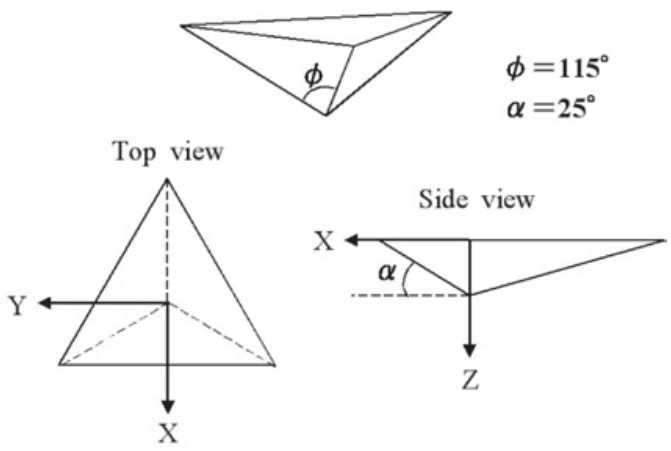

Fig. 3. Configuration of the Berkovich indenter.

the transmitted bar. The stress waves can be measured by a foil strain gage (KYOWA, KFG-2-120-C1-11) and a semiconductor strain gage (KYOWA, KSP-1-350-E4) attached to the incident bar and the transmitted bar.

By applying the elementary one-dimensional elastic wave propagation theory, we can determine the nominal stress $\sigma(t)$, the nominal strain $\varepsilon(t)$, and the strain rate $\dot{\varepsilon}(t)$ in the specimen as follows:

$$
\begin{gathered}
\sigma(t)=\frac{A E}{A_{\mathrm{s}}} \varepsilon_{\mathrm{t}}(t) \\
\varepsilon(t)=\frac{2 c_{0}}{l_{s}} \int_{0}^{t}\left[\varepsilon_{\mathrm{i}}(t)-\varepsilon_{\mathrm{t}}(t)\right] d t \\
\dot{\varepsilon}(t)=\frac{2 c_{0}}{l_{s}}\left[\varepsilon_{\mathrm{i}}(t)-\varepsilon_{\mathrm{t}}(t)\right]
\end{gathered}
$$

where $A$ is the cross-sectional area of the specimen, $A_{\mathrm{s}}$ is the cross-sectional area of the elastic bars, $E$ is Young's modulus of the incident and transmitted bars, $C_{0}$ is the velocity of the elastic wave in the incident and transmitted bars $\left(c_{0}=\sqrt{E / \rho} \cong 5000 \mathrm{~m} / \mathrm{s}, \rho\right.$ : density of the incident and transmitted bars), and $\varepsilon_{\mathrm{i}}(t)$ and $\varepsilon_{\mathrm{t}}(t)$ are the incident and transmitted waves, respectively.

In the present study, an average strain rate of the impact test was approximately $1.1 \times 10^{3} \mathrm{~s}^{-1}$, as calculated by equation (4).

Both the QS test and the impact test were carried out at room temperature.

\subsection{Micro-indentation test}

Experiments were carried out using a micro-indentation testing machine, DUH201, supplied by SHIMADZU CORPORATION. The indenter was a Berkovich indenter with an edge angle of $\phi=115^{\circ}$, as shown Figure 3.

In the present study, the loading and unloading rates were $0.7,7$, and $70 \mathrm{mN} / \mathrm{s}$ at room temperature. The maximum load was $1200 \mathrm{mN}$, and then was maintained for $30 \mathrm{~s}$ before unloading (referred to hereinafter as the holding time).

All of the indentation tests were carried out in a stabilized case at a temperature variation of $\pm 0.1 \mathrm{~K}$. The number of tests was 10 . 


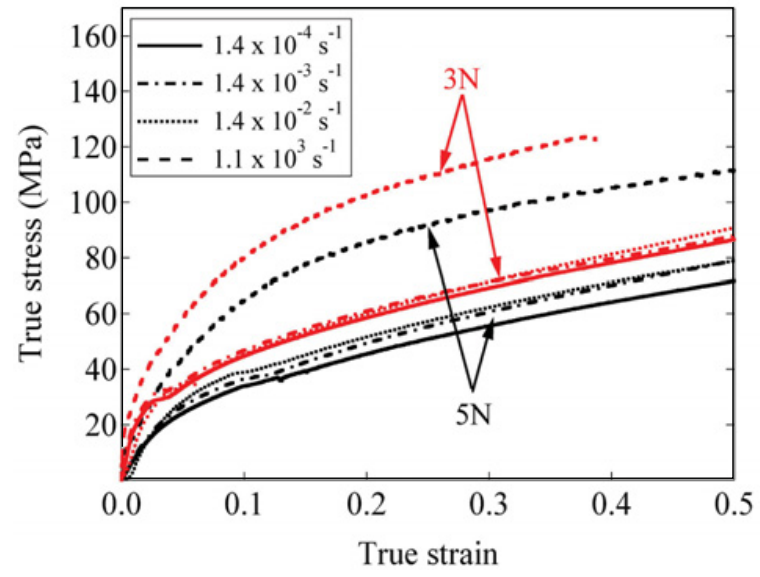

Fig. 4. True stress-strain curves for $3 \mathrm{~N}$ and $5 \mathrm{~N}$ aluminum in the QS test and the impact test.

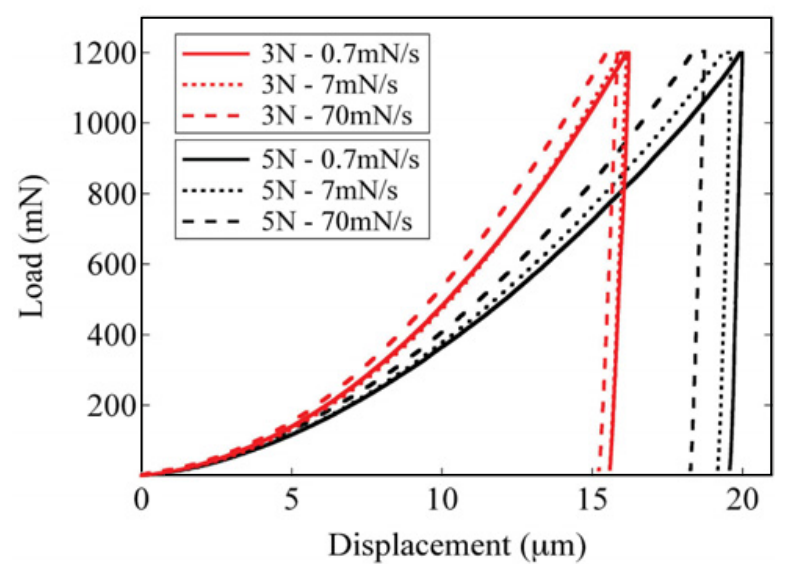

Fig. 5. Load-displacement curves for $3 \mathrm{~N}$ and $5 \mathrm{~N}$ aluminum in the indentation test.

\section{Results and discussion}

\subsection{Quasi-static and impact compression properties}

Figure 4 shows the typical true stress-strain curves for $3 \mathrm{~N}$ and $5 \mathrm{~N}$ aluminum in the QS test and the impact test. As a result of the compression test, the flow stress decreased when the aluminum purity was increased from $99.9 \%$ to $99.999 \%$, regardless of the strain rate.

In both $3 \mathrm{~N}$ and $5 \mathrm{~N}$ aluminum specimens, the flow stress was increased in the impact test as compared with the QS test. This trend is similar to the result reported by Holt et al. [13] whereby pure aluminum shows the strain rate sensitivity in the dynamic strain rate. However, in the QS test, the flow stress for $3 \mathrm{~N}$ aluminum showed no change with increasing strain rate, whereas that for $5 \mathrm{~N}$ aluminum increased, as described in detail later herein.

\subsection{Indentation properties}

\subsubsection{Load-displacement relationship}

Figure 5 shows the typical load-displacement curves for $3 \mathrm{~N}$ and $5 \mathrm{~N}$ aluminums in the indentation test. The load

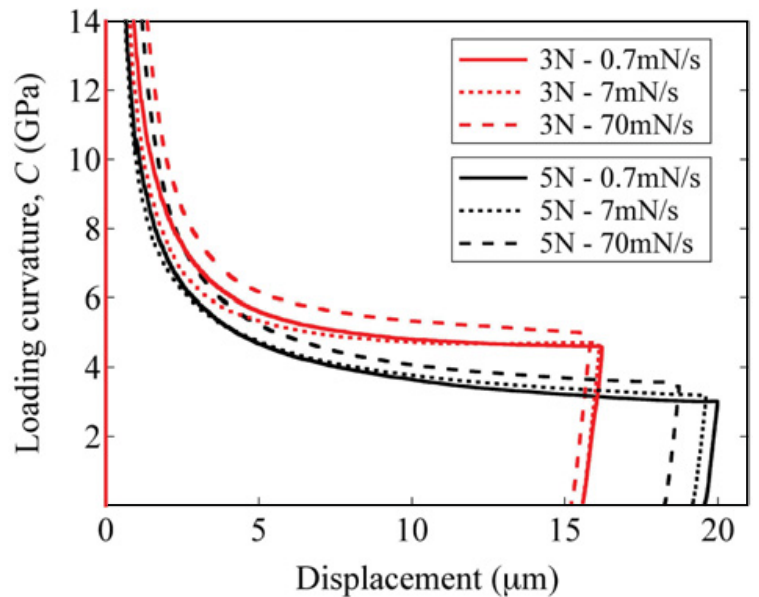

Fig. 6. Loading curvature-displacement relationship for $3 \mathrm{~N}$ and $5 \mathrm{~N}$ aluminum in the indentation test.

of the indentation test was decreased when the aluminum purity was increased, as with the QS and the impact compression test results. During the loading process for $3 \mathrm{~N}$ aluminum, the loads for the loading rates of $0.7 \mathrm{mN} / \mathrm{s}$ and $7 \mathrm{mN} / \mathrm{s}$ were almost identical. However, the load for the loading rate of $70 \mathrm{mN} / \mathrm{s}$ was higher than those for the loading rates of $0.7 \mathrm{mN} / \mathrm{s}$ and $7 \mathrm{mN} / \mathrm{s}$. On the other hand, for the $5 \mathrm{~N}$ aluminum, the load increased with increasing loading rate. Thus, it was revealed that the load of the micro-indentation test was affected by the loading rate.

\subsubsection{Loading curvature-displacement relationship}

In the indentation test, the loading segment of the loaddisplacement relationship obeys Kick's law as follows:

$$
P=C h^{2}
$$

where $C$ is the loading curvature, which is a constant value that depends on both the elasto-plastic properties of materials and the indenter angle.

Figure 6 shows the loading curvature-displacement relationship for $3 \mathrm{~N}$ and $5 \mathrm{~N}$ aluminum in the indentation test. For all of the loading rates, the loading curvature was not constant. The loading curvature was affected by the loading rate. The loading curvature decreased with increasing displacement immediately after indentation, and then this value was convergent, regardless of the loading rate. In both the $3 \mathrm{~N}$ and $5 \mathrm{~N}$ aluminum, the loading curvature value for the loading rate of $70 \mathrm{mN} / \mathrm{s}$ is larger than that for the loading rate of $0.7 \mathrm{mN} / \mathrm{s}$ and $7 \mathrm{mN} / \mathrm{s}$.

\subsubsection{Displacement during holding time at maximum load}

Figure 7 shows the relationship between the displacement during the holding time at maximum load (referred to hereinafter as the holding displacement) and the loading rate for $3 \mathrm{~N}$ and $5 \mathrm{~N}$ aluminum in the indentation test. The holding displacement increased with increasing loading rate for both $3 \mathrm{~N}$ and $5 \mathrm{~N}$ aluminum. Based on this finding, stress-relaxation became increasingly difficult as the 


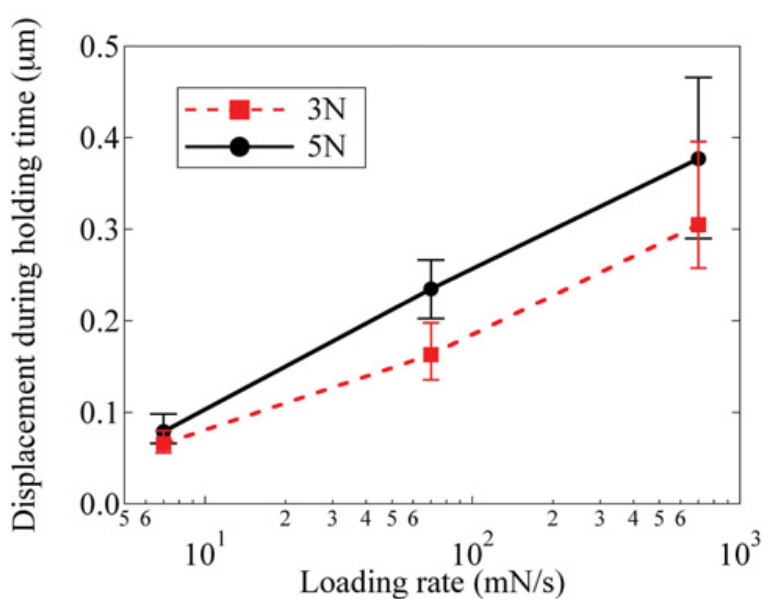

Fig. 7. Relationship between displacement during holding time at maximum load and loading rate for $3 \mathrm{~N}$ and $5 \mathrm{~N}$ aluminum in the indentation test.

loading rate increased. Thus, the holding displacement was increased, because this accumulation occurred in the holding time.

In addition, the holding displacement for the loading rate of $0.7 \mathrm{mN} / \mathrm{s}$ was approximately the same for $3 \mathrm{~N}$ and $5 \mathrm{~N}$ aluminum. However, the holding displacement for $5 \mathrm{~N}$ aluminum was higher than that for $3 \mathrm{~N}$ aluminum when the loading rate was higher than $7 \mathrm{mN} / \mathrm{s}$. In recent studies $[14,15]$, the holding displacement was used by indentation creep test, which was affected by the testing temperature and the strain rate. In the present study, the effect of high strain rate on the holding displacement appeared for both $3 \mathrm{~N}$ and $5 \mathrm{~N}$ aluminum.

\subsection{Relationship between loading rate and strain rate}

In both $3 \mathrm{~N}$ and $5 \mathrm{~N}$ aluminum, the true stress-true strain relationship, as shown Figure 4, was investigated in detail, because the indentation properties were affected by the variation of the loading rate. Figure 8 shows the effect of strain rate on true stress at each true strain $(\varepsilon=0.05,0.15$, 0.20 , and 0.30 ) in $3 \mathrm{~N}$ and $5 \mathrm{~N}$ aluminum. The strain rate dependence of the flow stress of $3 \mathrm{~N}$ and $5 \mathrm{~N}$ aluminum represents using the logarithm of the strain rate, as shown Figure 8. Comparing the true stress at each true strain for $3 \mathrm{~N}$ aluminum and $5 \mathrm{~N}$ aluminum revealed that the trend of the QS test was different.

Thus, the rate of increase in the true stress at each true strain, which was caused by the increasing strain rate, was calculated using the least squares method. In the present study, this rate of increase was defined as the strain rate sensitivity. Table 1 shows the strain rate sensitivity at each true strain obtained from Figure 8 for $3 \mathrm{~N}$ and $5 \mathrm{~N}$ aluminum, where $\alpha$ and $\beta$ are the strain rate sensitivity of the QS test and the strain rate sensitivity of the comparison with QS $\left(1.4 \times 10^{-2} \mathrm{~s}^{-1}\right)$ and the impact test, respectively. In both $3 \mathrm{~N}$ and $5 \mathrm{~N}$ aluminum, $\beta$, which indicates that the strain rate dependence of strength between the QS and impact deformation, was high, as shown Section 3.1.

On the other hand, for the $3 \mathrm{~N}$ aluminum, $\alpha$ was very small and did not exhibit the strain rate dependence of

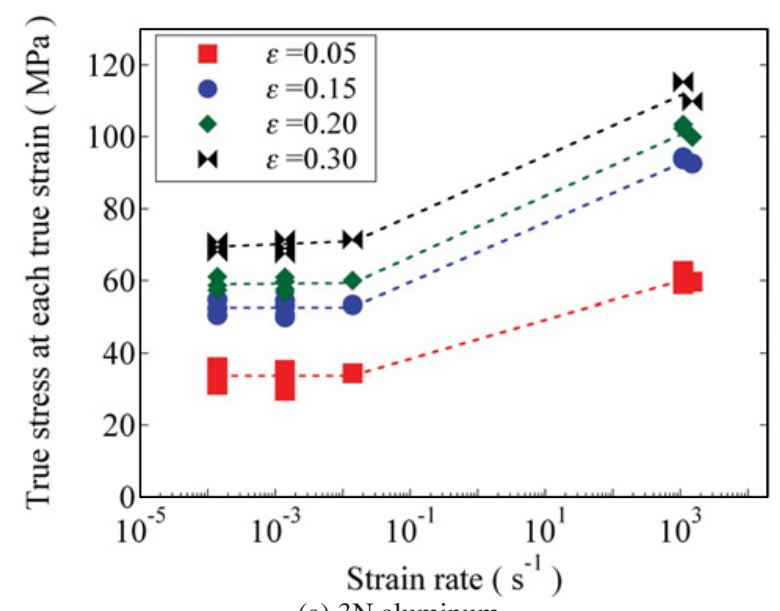

(a) $3 \mathrm{~N}$ aluminum

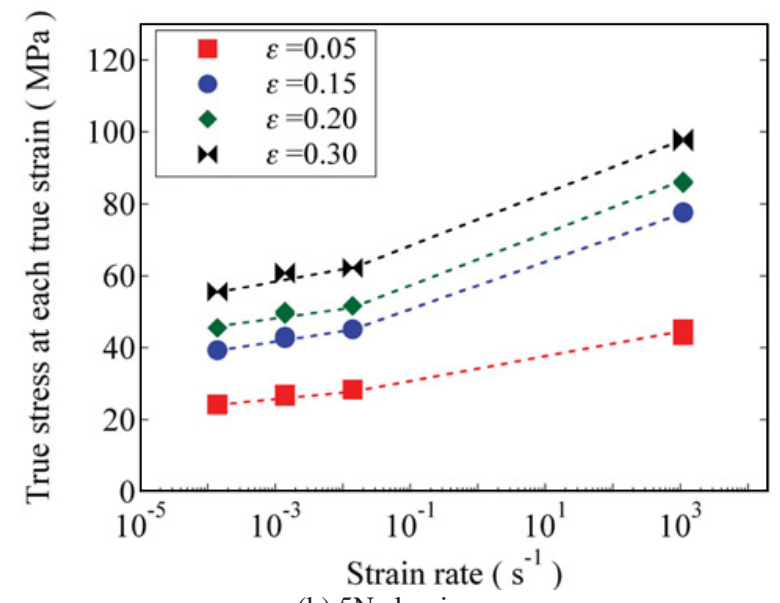

(b) $5 \mathrm{~N}$ aluminum

Fig. 8. Effect of strain rate on true stress at each true strain in $3 \mathrm{~N}$ and $5 \mathrm{~N}$ aluminum.

Table 1. Strain rate sensitivity at each true strain obtained from Fig. 8 in $3 \mathrm{~N}$ and $5 \mathrm{~N}$ aluminum. $\alpha$ : QS test, $\beta$ : comparison with QS $\left(1.4 \times 10^{-2} \mathrm{~s}^{-1}\right)$ and the impact test.

\begin{tabular}{|l|c|c|c|c|}
\hline & \multicolumn{2}{|c|}{$3 \mathrm{~N}$} & \multicolumn{2}{c|}{$5 \mathrm{~N}$} \\
\hline$\varepsilon$ & $\alpha$ & $\beta$ & $\alpha$ & $\beta$ \\
\hline 0.05 & 0.00 & 2.29 & 0.91 & 1.41 \\
\hline 0.15 & 0.03 & 3.53 & 1.25 & 2.89 \\
\hline 0.20 & 0.12 & 3.67 & 1.34 & 3.05 \\
\hline 0.30 & 0.38 & 3.68 & 1.45 & 3.15 \\
\hline
\end{tabular}

strength in the QS test. Compared to $3 \mathrm{~N}$ aluminum, the value of $\alpha$ for the $5 \mathrm{~N}$ aluminum was higher. It has been reported [13] that the effect of decreased alloying or purity is a decrease in the athermal stress component, which induce increased strain rate sensitivity in $\mathrm{O}$ tempered aluminum using the thermally activated process concept. Thus, the results obtained in the present study were related to aluminum purity.

In the experiments, the effect of loading rate on load during indentation, as shown Figure 5, was in agreement with the trend of the strain rate dependence of flow stress for the QS test for loading rates of $0.7 \mathrm{mN} / \mathrm{s}$ and $7 \mathrm{mN} / \mathrm{s}$ for $3 \mathrm{~N}$ and $5 \mathrm{~N}$ aluminum. A loading rate of up to $7 \mathrm{mN} / \mathrm{s}$ may reveal the QS strain rate. On the other hand, the indentation 
test for a loading rate of $70 \mathrm{mN} / \mathrm{s}$ reached a high strain rate, indicating a dynamic strain rate, in pure aluminum, as shown in the previous study using pure copper [6]. Thus, the micro-indentation test was strongly affected by dynamic strain rate at a loading rate of $70 \mathrm{mN} / \mathrm{s}$.

\section{Summary}

In order to clarify the effect of high strain rate on the micro-indentation test, the indentation properties of pure aluminum with strain rate dependence of strength was investigated experimentally. The obtained results are summarized as follows. (1) The strain rate dependence of flow stress for $5 \mathrm{~N}$ aluminum was higher than that for $3 \mathrm{~N}$ aluminum in both the QS test and the impact test. (2) In $3 \mathrm{~N}$ and $5 \mathrm{~N}$ aluminum, the effect of loading rate on the indentation properties was similar to the strain rate dependence of flow stress. (3) The micro-indentation test was strongly affected by the dynamic strain rate at a loading rate of $70 \mathrm{mN} / \mathrm{s}$.

\section{Acknowledgements}

The financial support by the Japan Aluminum Association is greatly appreciated. The authors are deeply grateful to Mr. Ishii (undergraduate student at the National Defense Academy) for his help in the present study.

\section{References}

1. Y.T. Cheng, C.M. Cheng, Mater. Sci. Eng. R44, 91 (2004).

2. A. Gouldstone, N. Chollacoop, M. Dao, J. Li, A.M. Minor, Y.-L. Shen, Acta Mater. 55, 4015 (2007).

3. N. Ogasawara, X. Chen, N. Chiba, J. Mater. Res., 21, 947 (2006).

4. M.F. Doerner, W.D. Nix, J. Mater. Res., 1, 601 (1986).

5. E. Harsono, S. Swaddiwudhipong, Z.S. Li,L. Shen, Int. J. Solids Structures, 48, 972 (2011).

6. H. Yamada, N. Ogasawara, Y. Shimizu, Proc. JSME 24th Comp. Mech. Div. Conf., 578 (2011).

7. N. Ogasawara, C. Kuramochi, W. Makiguchi, N. Chiba, Trans. JSME A, 69, 805 (2003).

8. H. Kolsky, Proc. Phys. Soc. B, 62, 676 (1949).

9. B. Hopkinson, Phil. Trans. A, 213, 437(1914).

10. K. Ogawa, J. J. Inst. of L. M., 51, 175 (2001) 175.

11. K. Ogawa, H. Kobayashi, F. Sugiyama, K. Horikawa, JSME Int. J. A, 48, 228 (2005).

12. W. Johnson: IMPACT STRENGTH OF MATERIALS, (Edward Arnold, London, 1972).

13. D.L. Holt, S.G. Babcock, S.J. Green, C.J. Maiden, Trans. of ASM, 60, 152 (1967).

14. R. Goodall, T.W. Clyne, Acta Mater., 54, 5489 (2006).

15. K. Sakaue, S. Okazaki, T. Ogawa, Trans. JSME A, 75, 1045 (2009). 